\title{
Estudo anatôMico da flor de MARSDENIa LONICERoIdes E. FourNIER (AsClePiadoideaE- APOCYNACEAE) ${ }^{1}$

\author{
Maria da Conceição Valente ${ }^{1,2,3}$ \& Cecília Gonçalves Costa ${ }^{2}$
}

\section{Resumo}

(Estudo anatômico da flor de Marsdenia loniceroides E. Fournier (Asclepiadoideae - Apocynaceae)) Este trabalho visa contribuir para o melhor conhecimento da flor de Marsdenia loniceroides e fornecer subsídios à taxonomia de Asclepiadoideae. São apresentados dados relativos ao desenvolvimento e à anatomia floral da espécie e é analisada a origem da corona e dos transladores, assim como das estruturas localizadas entre as sépalas e o tubo da corola, que são consideradas emergências glandulares. As coronas de Marsdenia loniceroides têm origem estaminal e são desprovidas de vascularização. Os transladores (retináculo e caudículas) são originados pela atividade secretora das células que revestem a cabeça estilar e as emergências glandulares têm origem na face interna das sépalas. Esses três aspectos - origem das coronas, formação dos transladores e origem e natureza das emergências - caracterizam a espécie em análise. Deve-se ressaltar que os demais aspectos anatômicos correspondem ao padrão da subfamília. Neste trabalho, denomina-se tubo floral ao conjunto formado pelo tubo da corola e pelo tubo estaminal.

Palavras-chave: Marsdenia loniceroides, Asclepiadoideae, anatomia floral, corona e translador.

\section{Abstract}

(Anatomical study of the flower of Marsdenia loniceroides E. Fournier (Asclepiadoideae - Apocynaceae)) This work aims to contribute to a better knowlodge about the Marsdenia loniceroides flower, with the objective of providing subsidies to taxonomy of the subfamily Asclepiadoideae. Data about the development and floral anatomy of this species is presented. It is analized the origin of the corona, translators and the structures situated between the sepals and corola tube. These structures are considered glandular emergences. Marsdenia loniceroides corona has staminal origin and it are not vascularizated. Translators (retinaculum and caudiculum) are originated by the cells secretory activity that covers the stylar head, and the glandular emergences are originated in sepals internal face. These aspects - corona's and translators' origin, emergences' origin and its constitution are characteristics of this species. It must be emphasized that the other anatomic aspects correspond to the subfamily pattern. In this work the set consisted by corola tube and staminal tube is considered floral tube. Key-words: Marsdenia loniceroides, Asclepiadoideae, floral anatomy, corona and translators.

\section{INTRODUÇÃo}

A subfamília Asclepiadoideae R. Br. ex Burnett está representada por aproximadamente 250 gêneros e 2.000 espécies, distribuídas nos cinco continentes. São plantas predominantemente volúveis, ocorrendo também arbustos e subarbustos de porte ereto. Até recentemente, era conferido a esse grupo o status de família - Asclepiadaceae - passando à subfamília, subordinada àfamília Apocynaceae, depois dos estudos de Endress \& Bruyns (2000).

As Asclepiadoideae chamam a atenção por sua diversidade morfológica e pela estrutura floral, dada a singular adaptação à polinização por insetos, que as distingue entre os grupos mais complexos das Angiospermas (Endress \& Bruyns 2000).
Diversos autores descreveram a morfologia das flores de Asclepiadaceae (Holm 1950; Woodson 1954; Safwat 1962; Cronquist 1981; Barroso et al. 1986; Rosatti 1989; Swarupanandan et al. 1996). Entretanto, devido à complexidade dessas flores, alguns restringiram seus estudos às características morfológicas de apenas uma tribo (Kunze 1995) ou de um verticilo floral (Liede \& Kunze 1993; Kunze 1996; Liede 1996) ou de uma estrutura floral (Kunze 1993, 1994).

Três estruturas florais nessa subfamília merecem particular atenção devido à sua complexidade e distribuição limitada entre as Angiospermas: o polinário, a cabeça estilar e a corona. Cada uma delas tem sido considerada

Artigo recebido em 03/2005. Aceito para publicação em 05/2005.

${ }^{1}$ Parte da Tese da primeira autora para o curso de Pós-Graduação em Botânica, Museu Nacional/UFRJ.

${ }^{2}$ Instituto de Pesquisas Jardim Botânico do Rio de Janeiro. Rua Pacheco Leão 915, 22460-030, Rio de Janeiro, RJ.

${ }^{3}$ Autor para correspondência: mvalente@ jbrj.gov.br 
como uma característica das Asclepiadoideae, embora estruturas homólogas (particularmente a cabeça estilar e a corona) sejam encontradas em algumas espécies de Apocynaceae (Fallen 1986; Kunze 1990; Judd et al. 1994; Sennblad \& Bremer 1996; Endress \& Bruyns 2000).

A corona é uma estrutura destinada à reserva de néctar e se localiza entre a corola e a cabeça estilar. Embora tenha sido tema de muitos estudos, as interpretações a respeito dessa estrutura são controversas, devido à diversidade de formas que ela assume e à dificuldade de se estabelecer o seu relacionamento com o tubo da corola ecom o tubo estaminal (Endress 1994).

Tanto o retináculo quanto as polínias apresentam grande variedade de forma e de tamanho. Por outro lado, as caudículas podem variar segundo sua inserção no retináculo e na polínia, ou apresentar dentes inclusos ou salientes. Estas características são utilizadas na taxonomia em nível genérico e/ou específico (Endress \& Bruyns 2000).

Este trabalho tem por objetivo contribuir para o conhecimento da estrutura floral de Marsdenia loniceroides E.Fournier, tendo em vista a inexistência de estudos focalizando tais aspectos. Pretende-se, pelos estudos da anatomia floral de Marsdenia loniceroides e do desenvolvimento das coronas e dos transladores fornecer subsídios para a taxonomia da subfamília.

\section{Material e Métodos}

O material botânico de Marsdenia loniceroides foi coletado no Morro de Santa Lúcia, em afloramento rochoso granítico, em Vitória, Espírito Santo, e está depositado no Herbário do Instituto de Pesquisas Jardim Botânico do Rio de Janeiro sob o $\mathrm{n}^{\circ} \mathrm{RB}$ 411.784.

Para a análise histológica foram coletados botões florais, em vários estádios de desenvolvimento, fixados em FPA em álcool etílico a $70 \%$ ou FAA, em álcool etílico $50 \%$ (Johansen 1940). O material foi processado de acordo com as técnicas usuais em estudos anatômicos (Johansen 1940). As lâminas permanentes foram coradas com safraninafast green, utilizando-se também o azul de astra e fucsina básica, segundo Roeser (1972) modificada por Luque et al. (1996).

Efetuaram-se testes histoquímicos, em botões florais recém coletados, para comprovar a presença de cutina e lignina e a natureza dos cristais. Foram utilizados Sudan IV para evidenciar cutícula e paredes cutinizadas, floroglucina em meio ácido para indicar a presença de lignina (Sass 1940), e os ácidos acético glacial e clorídrico e sulfúrico diluídos para detectar o oxalato de cálcio (Johansen 1940).

Para exame ao microscópio eletrônico de varredura, pequenos fragmentos do material foram fixados em paraformaldeido $4 \%$, glutaraldeido 2,5\%, em tampão PIPES 0,1 M, pós-fixado em tetróxido de ósmio $2 \%$. Após fixação, o material foi lavado três vezes em tampão e posteriormente desidratado em série crescente de acetona até 100\% (Hayat 1981), seguindo-se a secagem no aparelho de ponto crítico (Balzers/Union CPD 020). As amostras foram então montadas diretamente nos suportes adequados de alumínio e metalizadas com ouro. As análises foram observadas e fotografadas no microscópio eletrônico de varredura JEOL 5310, operado em $20 \mathrm{kV}$.

\section{Resultados}

\section{Desenvolvimento das peças flora is}

Nos primeiros estádios de desenvolvimento do botão floral de Marsdenia loniceroides observa-se, em secção longitudinal, a disposição das peças florais. Nesta fase de diferenciação, a porção dilatada na base corresponde à junção do pedicelo e do receptáculo, visualizando-se, mais acima, o tubo da corola, ainda unido ao tubo estaminal para formar o tubo floral, os dois carpelos e, em nível superior, a cabeça estilar e o prolongamento do apêndice estilar (Fig. 1).

As diversas fases de individualização das peças florais podem ser acompanhadas em secções transversais, efetuadas em diferentes níveis do botão floral (Fig. 1). 

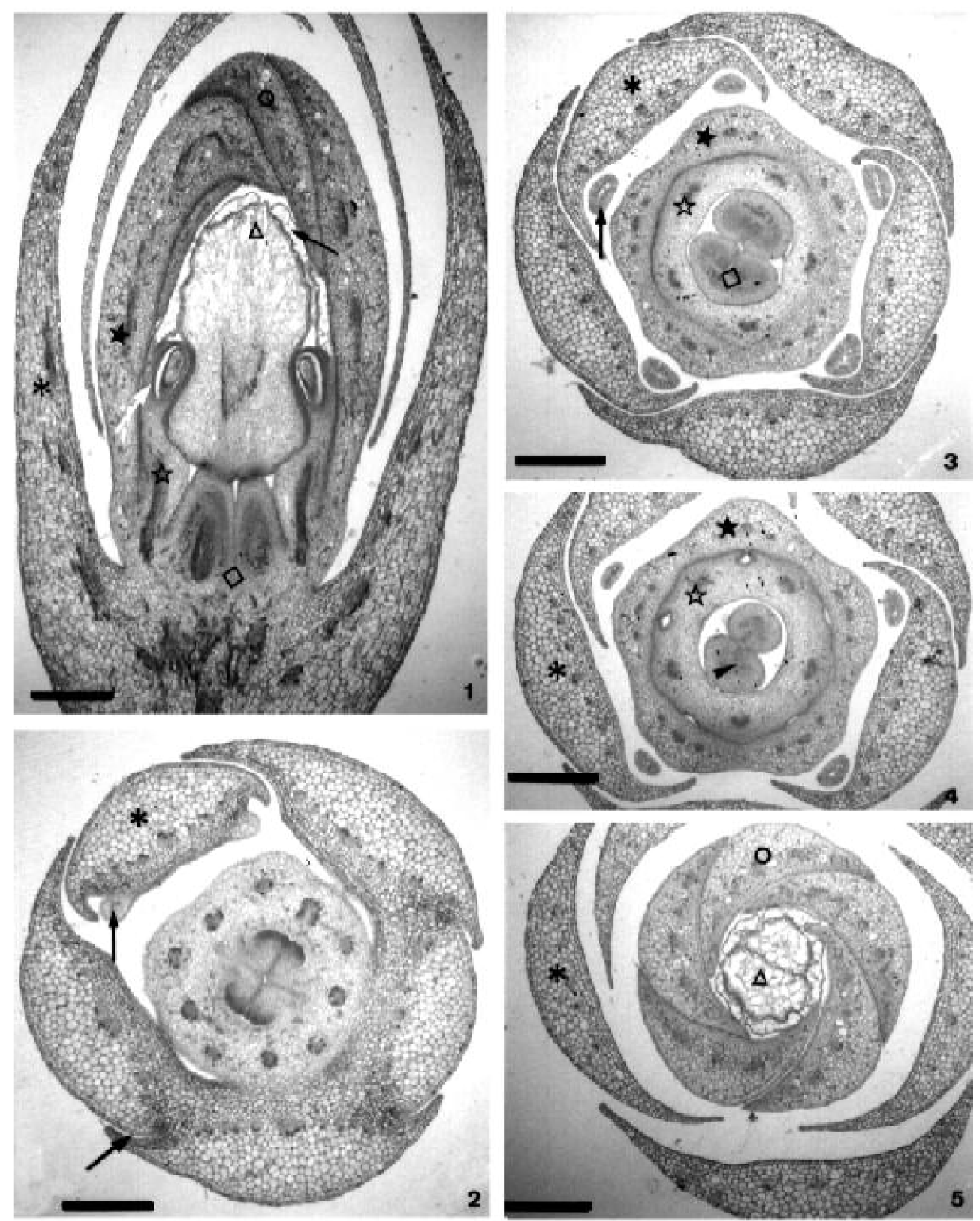

Figuras 1-5 - Botão floral (SLe ST): 1 - disposição das peças florais (SL); 2 - fendas que iniciam o processo de individualização das sépalas, início da diferenciação de duas emergências glandulares; 3 - prefloração quincuncial e emergências glandulares já diferenciadas; 4 - tubo da corola e tubo estaminal individualizados; 5 - lacínias da corola já individualizadas. $(1$ : barra $=300 \mu \mathrm{m} ; 2$ a 5: barra $=200 \mu \mathrm{m}) \mathrm{SL}=$ secção longitudinal; $\mathrm{ST}=$ secção transversal; antera $=\succsim$; apêndice estilar $=r$; apêndice membranáceo $=\%$ apêndice do ovário $=$ Ü ; emergência glandular $=\#$, fendas $=\& ;$ lacínias da corola $={ }^{\circ} ;$ sépala $=>;$ tubo corola $=$; tubo estaminal $=\partial ;$ ovário $=\varnothing$. 
A individualização das sépalas tem inicio com o surgimento de duas pequenas fendas na superfície externa do botão floral, que gradativamente se aprofundam, até completa separação (Fig. 2). Ao mesmo tempo, ocorre a diferenciação de emergências glandulares, que se originam nas regiões laterais da face adaxial das sépalas internas (Fig. 2) e da sépala intermediária.

Paralelamente, o tubo floral se destaca da superfície interna das sépalas (Fig. 2) e, posteriormente, separa-se dos carpelos (Fig. 3); numa etapa seguinte, ocorre a individualização do tubo da corola e do tubo estaminal (Fig. 4). Em fase posterior de desenvolvimento, e em nível mais elevado, as lacínias da corola já se mostram individualizadas (Fig. 5). Anteriormente, já se evidenciava a prefloração quincuncial de Marsdenia loniceroides, caracterizada pela posição das sépalas, em que duas delas se localizam externamente, duas internamente $\mathrm{e}$ a quinta ocupa posição intermediária (Fig. 3). Ao mesmo tempo, eram visualizadas as emergências glandulares, que ocorrem, duas a duas, na superfície adaxial das sépalas internas e apenas uma, na sépala intermediária (Fig. 3 ). A mesma figura revela que as duas sépalas externas são desprovidas de tais estruturas.

Em fase anterior à individualização das lacínias da corola, os estiletes já se apresentam livres no ápice do ovário (Fig. 4). Os dois carpelos, que em nível basal mostravam-se livres, unem-se mais acima na região estilar, para formar, junto com as anteras, a cabeça estilar pentagonal, que caracteriza a família (Fig. 8).

Por sua vez, os estames se destacam, seqüencialmente, do tubo estaminal, liberandose, também do tubo da corola (ainda indiviso), e da cabeça estilar (Figs.6 e 8). A liberação dos estames tem início na face abaxial do tubo estaminal, através de pequenas invaginações (Fig. 7) que se aprofundam e se estendem, até a face oposta do tubo (Fig. 8). Tais invaginações são ladeadas por duas projeções aliformes que aumentam progressivamente, vindo a constituir as asas das anteras (Fig. 9).
Na região dorsal dos estames, surgem maciços celulares que vão dar origem aos segmentos das coronas (Figs. 10, 11 e 21). Em nível mais alto, no dorso das anteras, surgem apêndices membranáceos que se desenvolvem e ultrapassam o ápice das mesmas (Fig. 21).

As anteras localizam-se em oposição à face con vexa da cabeça estilar, sendo que no nível evidenciado na figura 12 , as polínias são visualizadas nos lóculos das anteras e, um pouco mais acima, já são observadas fora dos mesmos, após a abertura dos estômios (Fig. 13). As polínias apresentam-se eretas e se prendem à região basal das caudículas.

A cabeça estilar é visualizada após a liberação dos estames (Figs. 14 e 22) como uma estrutura de forma pentagonal, cujos ângulos progressivamente se projetam, pela atividade meristemática das células subepidérmicas, dando origem a uma protuberância (Fig. 15).

Nesta fase de desenvolvimento, todas as peças florais já estão individualizadas, sendo possível observar, em secções transversais e longitudinais, que o prolongamento do apêndice estilar, levemente bifurcado, ultrapassa os apêndices membranáceos das anteras (Figs. 1 e 6).

\section{Descrição anatômica}

A epiderme do pedicelo é uniestratificada, constituída de células cuja forma e tamanho são variados, e se encontram revestidas por cutícula delgada e lisa; nota-se a presença de tricomas pluricelulares. Sob a epiderme ocorrem dois a três estratos de colênquima angular, com células de paredes pouco espessadas e cinco a seis estratos de células parenquimáticas, heterodimensionais, de paredes delgadas. O cilindro vascular é constituído por grupos de feixes bicolaterais dispostos em círculo; o floema externo e interno apresenta-se em cordões, integrados por elementos de tubo crivado, células companheiras e células de parênquima floemático; o xilema dispõe-se em séries radiais de dois a três elementos vasculares, separados 


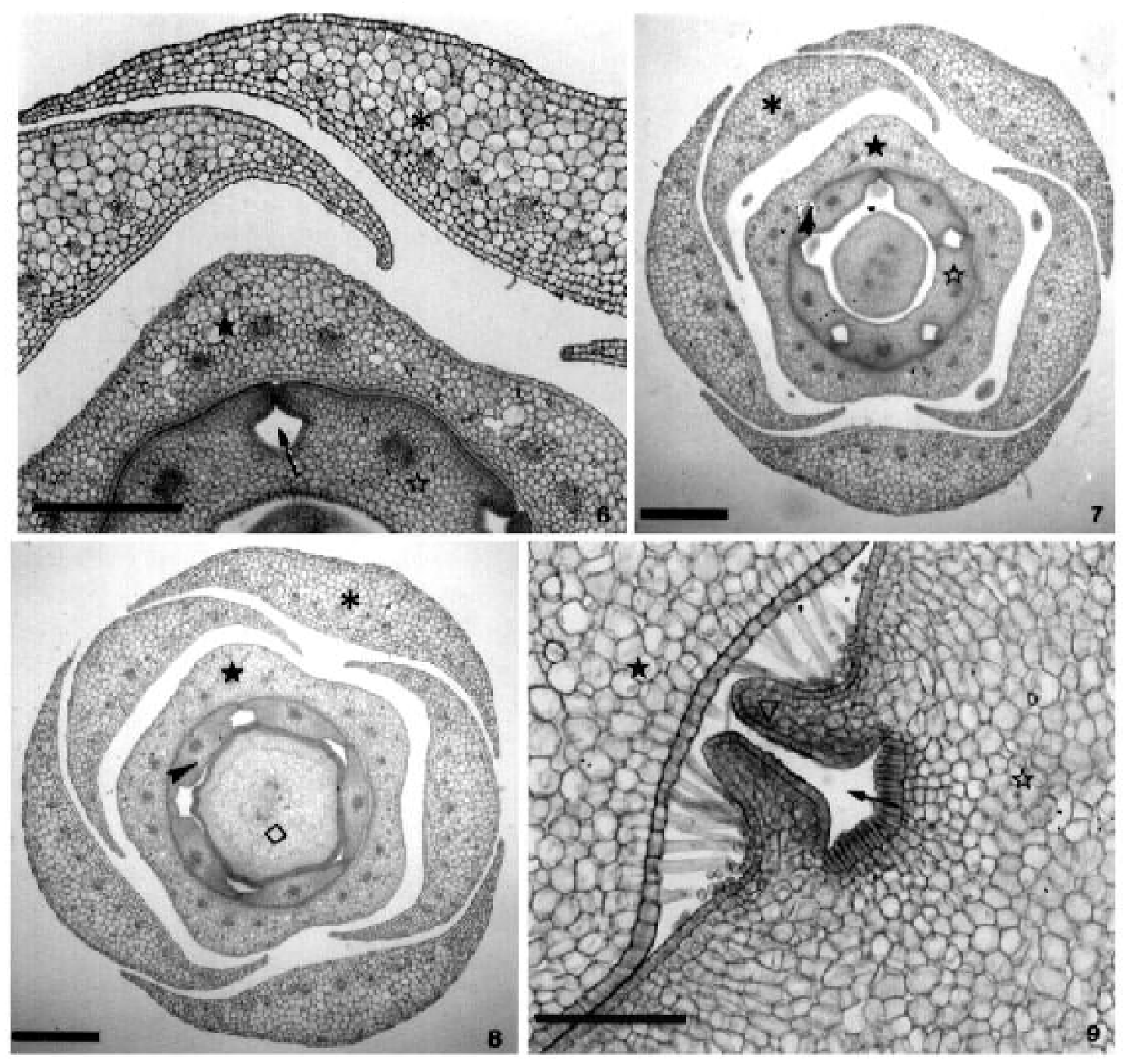

Figuras 6-9 - Botão floral(ST): 6 - tubo da corola ainda indiviso e liberação seqüencial dos estames; 7 - invaginações na face abaxial do tubo estaminal; 8 - seqüência da liberação dos estames; 9 - início das projeções aliformes precursoras das asas das anteras. (6 e 8: barra $=300 \mu \mathrm{m} ; 7$ e 9: barra $=200 \mu \mathrm{m}) \mathrm{ST}=$ secção transversal; cabeça estilar $=\varnothing$; estame $=\ddot{U} ;$ invaginação $=\%$ lacínias da corola $={ }^{\circ}$; protuberância $=r$; sépala $=>$; tubo corola $={ }^{\prime} ;$ tubo estaminal $=\partial$.

por células parenquimáticas. A região medular é constituída por células parenquimáticas heterodimensionais, com paredes delgadas.

O receptáculo, em secção transversal, apresenta contorno circular, com epiderme uniestratificada de célu las retangulares, cujas paredes periclinais externas são revestidas por cutícula delgada e lisa. Tricomas pluricelulares e raros estômatos estão situados ao mesmo nível das demais células epidérmicas. Em posição subepidérmica, ocorrem duas a três camadas de células colenquimáticas de paredes pouco espessadas, e parênquima em vários estratos, com células heterodimensionais, ocorrendo entre elas, laticíferos contínuos. O sistema vascular apresenta-se em grupos de feixes bicolaterais, que emitem os primeiros traços para as peças florais. As características dos elementos floemáticos e xilemáticos assemelham-se às do pedicelo. A medula apresenta células heterodimensionais de paredes delgadas (Fig. 16). 

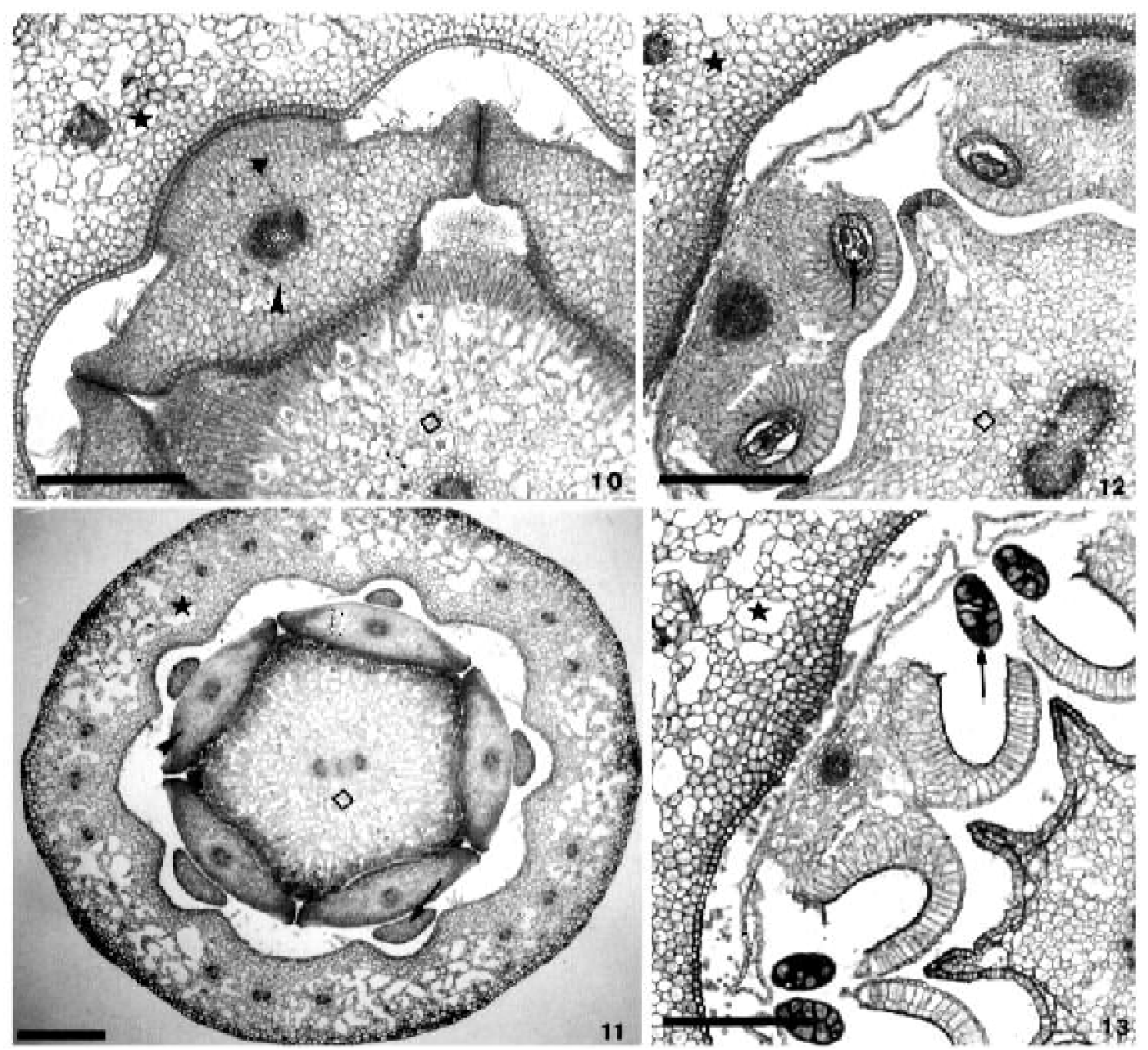

Figuras 10-13 - Botão floral (ST): 10 - etapa da diferenciação dos maciços celulares, precursores das coronas, no dorso dos estames; 11 - segmentos livres das coronas já individualizados; 12 - polínias visualizadas nos lóculos das anteras; 13 - polínias já formadas, situadas em lóculos de anteras adjacentes após a abertura dos estômios. $(10,12$ e 13: barra $=200 \mu \mathrm{m} ; 11$ : barra $=300 \mu \mathrm{m}) \mathrm{ST}=$ secção transversal ; antera $=ð$; cabeça estilar $=\varnothing$; corona $=\mathrm{I} ;$ estame $=\ddot{U} ;$ maciço celular $=5 ;$ polínia $=$ \#, tubo corola $={ }^{\prime}$.

Sépalas com epiderme uniestratificada, integrada por células de contorno retangular, na face adaxial, e cuja forma e tamanho são variáveis na face abaxial; cutícula delgada, sem ornamentações; raros estômatos, ao mesmo nível das demais células epidérmicas. No bordo, a epiderme tem características semelhantes, revestindo apenas um estrato parenquimático. Mesofilo integrado por células parenquimáticas, heterodimensionais, com paredes delgadas; tubos laticíferos e cinco a seis minúsculos feixes vasculares colaterais, próximos à face adaxial (Fig. 17).
As emergências glandulares, que ocorrem entre as sépalas e o tubo floral, são avascularizadas, e constituídas externamente por epiderme secretora, uniestratificada, com células em paliçada, de cutícula delgada; internamente ocorrem células parenquimáticas, heterodimensionais (Figs. 17e 31).

A epiderme do tubo da corola, na face adaxial, é uniestratificada, com células retangulares, de cutícula delgada; estômatos um pouco acima das demais células epidérmicas e tricomas, nas depressões opostas às projeções aliformes do tubo estaminal (Figs. 


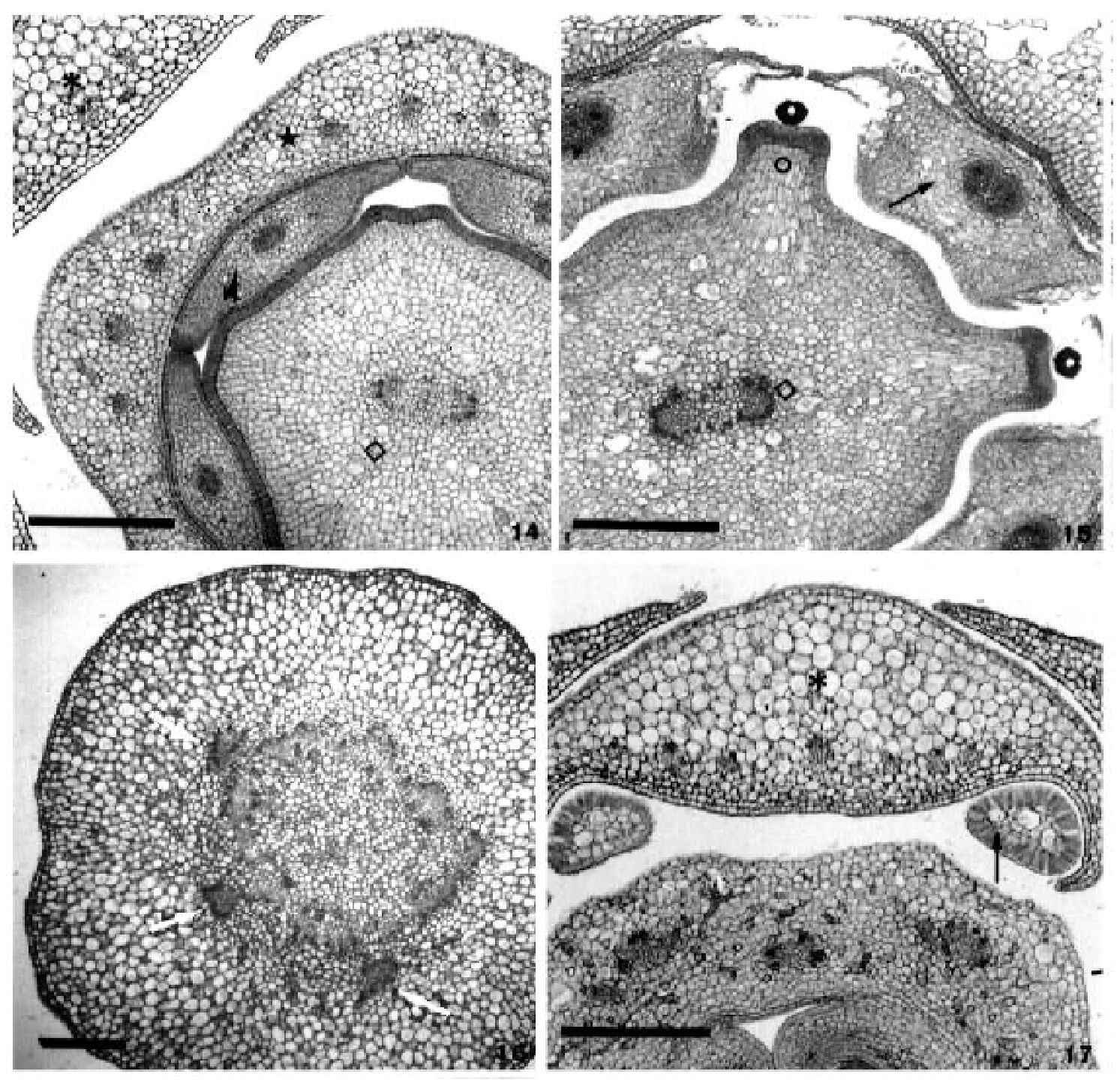

Figuras 14-17 - Botão floral (ST): 14 - cabeça estilar; 15 - protuberância secretora da cabeça estilar; 16 receptáculo, vendo-se feixes bicolaterais e primeiros traços florais; 17 - mesófilo e disposição dos feixes vasculares nas sépalas, emergências glandulares. $(14,15$ e 17 : barra $=200 \mu \mathrm{m} ; 16$ : barra $=300 \mu \mathrm{m}) \mathrm{ST}=$

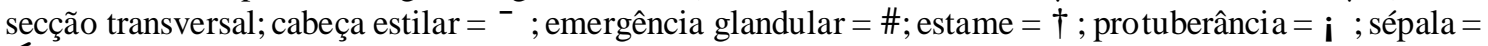
$>$; traços florais $=$ ठ ;ubo corola $={ }^{\prime}$.

9, 18 e 32). Na face abaxial, observam-se células de forma e tamanho variados, com cutícula delgada, estrias epicuticulares pouco conspícuas. Subjacente à epiderme abaxial, ocorre um aerênquima, com células braciformes; na face adaxial, o parênquima apresenta-se compacto, em cinco a seis camadas celulares; 15 feixes vasculares, em cinco grupos de três feixes, estão localizados nas regiões opostas às depressões do tubo estaminal (Figs. 9 e 18).
As expansões laminares que delimitam essas depressões constituem o início das asas das anteras (Fig. 19). A epiderme desse tubo é constituída de células retangulares, com cutícula delgada e lisa. Nas depressões, que se estendem longitudinalmente no tubo estaminal, a epiderme tem características secretoras e suas células assemelham-se a uma paliçada (Figs. 9 e 19). O mesofilo do tubo estaminal é constituído por várias camadas de células parenquimáticas, e é 

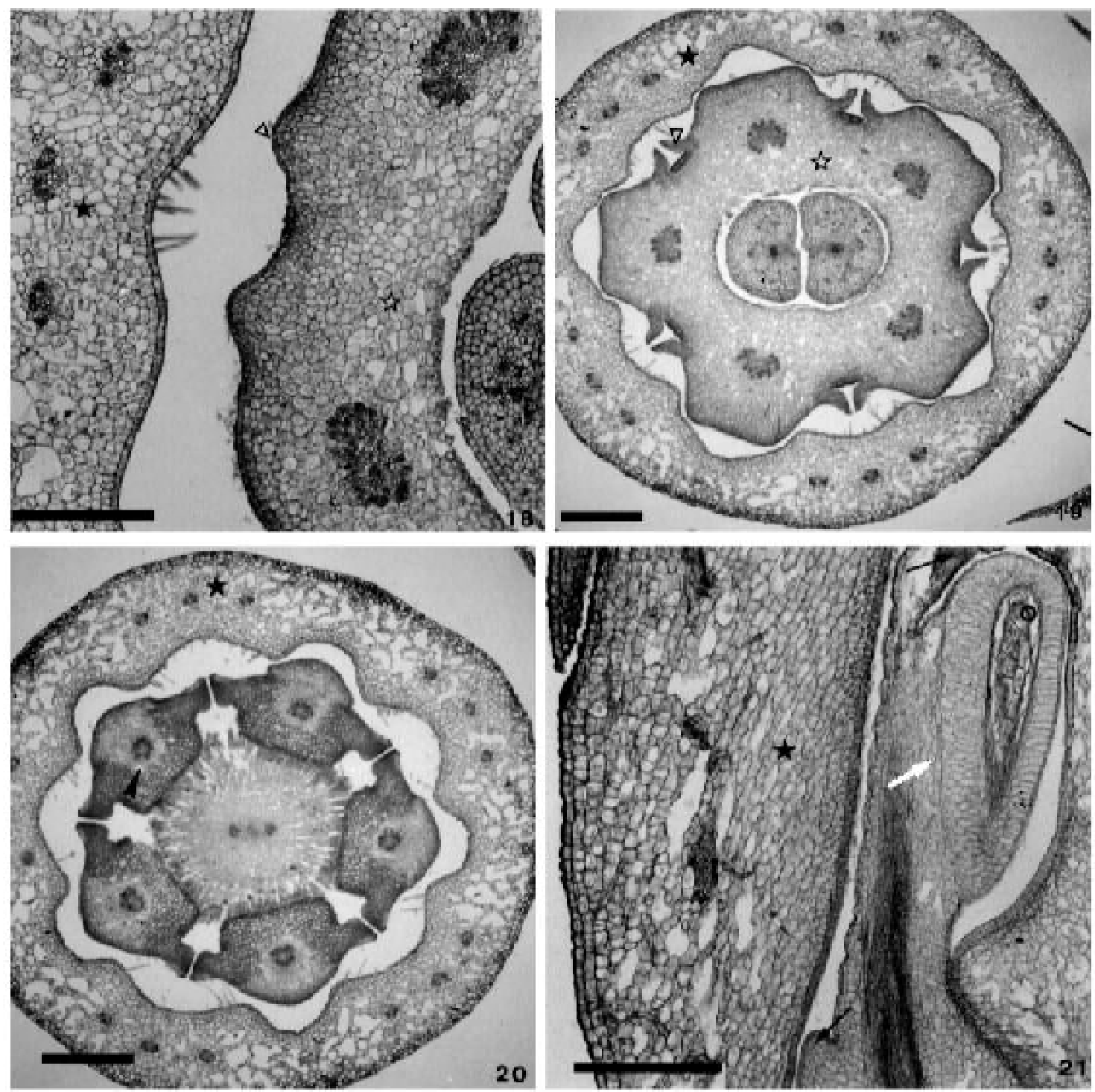

Figuras 18-21 - Botão floral (ST), 21 - (SL): 18 - início das projeções aliformes na face adaxial do tubo estaminal; 19 - tubo da corola indiviso, jáliberado do tubo estaminal, aerênquimano mesófilo; 20 - estames já individualizados; 21 - detalhe do segmento da corona, visualizado como expansão dorsal da antera. (18 e 21: barra= $200 \mu$ m; 19-20: barra $=300 \mu \mathrm{m}) \mathrm{SL}=$ secção longitudinal; $\mathrm{ST}=$ secção transversal; antera $=$ ठ ; corona $=\mathrm{I}$; depressão $=r$; estame $=\ddot{U} ;$ polínia $={ }^{\circ}$; tubo corola $={ }^{\prime}$; tubo estaminal $=\partial$.

vascularizado por cinco feixes vasculares bicolaterais.

$\mathrm{Na}$ face adaxial dos estames e nas expansões laminares, as células parenquimáticas apresentam paredes espessas e lignificadas; na face abaxial, tais células conservam as características iniciais e na região central, ocorre um feixe vascular bicolateral (Fig. 20).

No dorso de cada estame, ocorrem maciços celulares, visualizados em secção longitudinal na figura $21 \mathrm{e} \mathrm{em} \mathrm{microscopia} \mathrm{ele-}$ trônica de varredura (Fig. 30). Gradativamente, esses maciços se individualizam para constituir os segmentos da corona (Fig. 22), que não são vascularizados e cuja epiderme consiste de células retangulares, com cutícula delgada.

Em nível mediano do ovário, observa-se a placen tação marginal dos carpelos à qual se prendem os óvulos anátropos (Fig. 23). As 

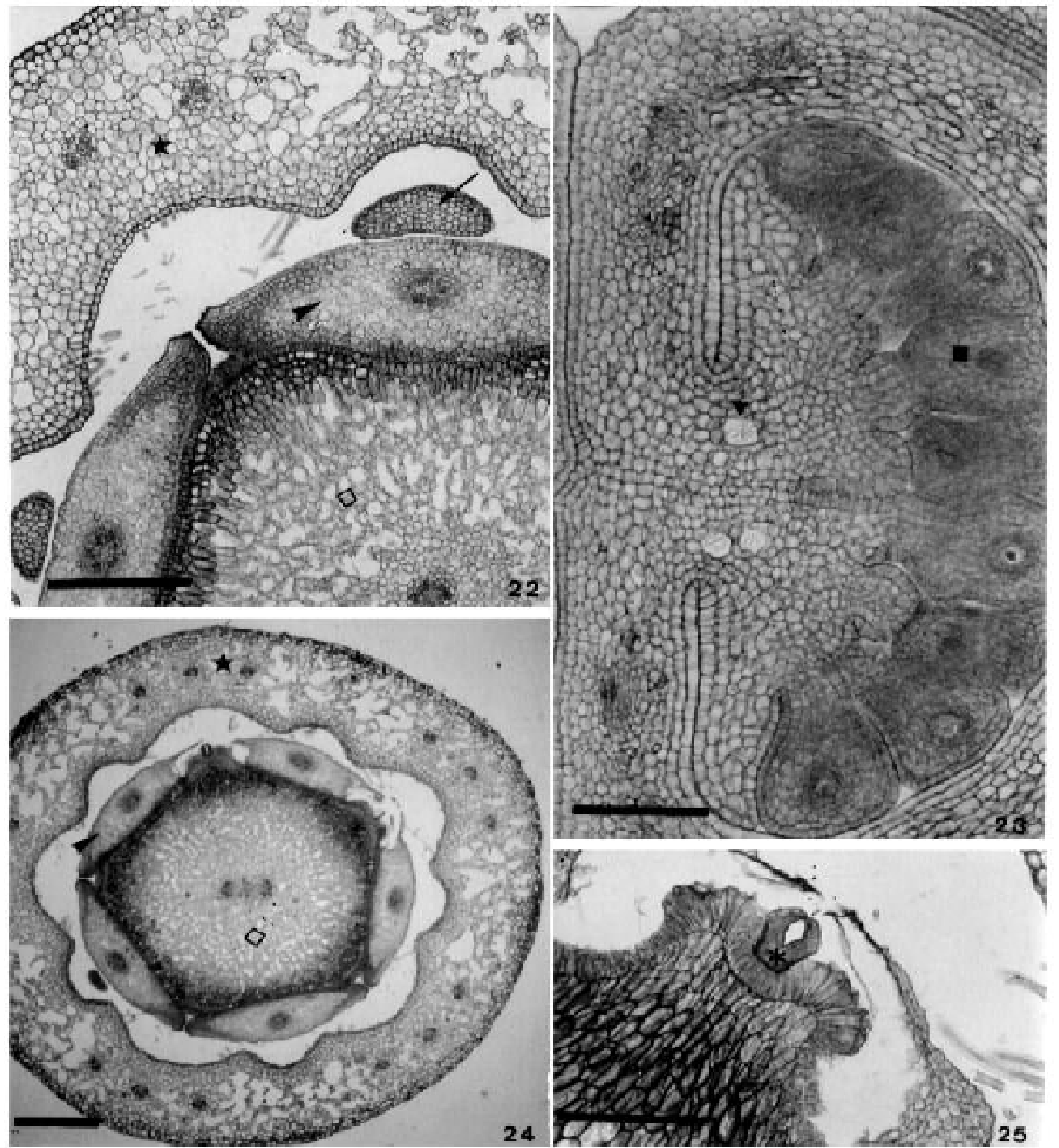

Figuras 22-25 - Botão floral (ST): 22 - segmentos da corona, não vascularizados; 23 - placentação marginal dos carpelos, com óvulos anátropos; idioblastos cristalíferos com drusas de oxalato de cálcio, feixes vasculares e laticíferos contínuos; 24 - cabeça estilar e estames, envolvidos pelo tulo da corola; 25 - projeção da cabeça estilar, com epiderme secretora, retináculo já diferenciado. $(22-23$ e 25 : barra $=200 \mu \mathrm{m}$; 24 : barra= $300 \mu \mathrm{m}) \mathrm{ST}$ $=$ secção transversal; cabeça estilar $=\varnothing ;$ corona $=\mathrm{I} ;$ estame $=\ddot{U} ;$ idioblasto critalífero $=r$; retináculo $=>$; tubo corola $=$ ' ; óvulo $={ }^{\circ}$.

paredes carpelares e as regiões placentárias são constituídas por parênquima compacto de células pequenas, com paredes delgadas, ocorrendo idioblastos com drusas de oxalato de cálcio; o tecido nutridor do óvulo é constituído por parênquima com características semelhantes (Fig. 23).

Rodriguésia 56 (87): 51-66. 2005
Em cada carpelo, dependendo donível da secção, ocorrem nove ou dezfeixes vasculares colaterais, sendo três mais desenvolvidos. Dois destes feixes, os marginais secundários, estão situados na base da placenta e o maior, o feixe dorsal, localiza-se na face oposta (Fig. 23). Entre eles ocorrem laticíferos contínuos. 

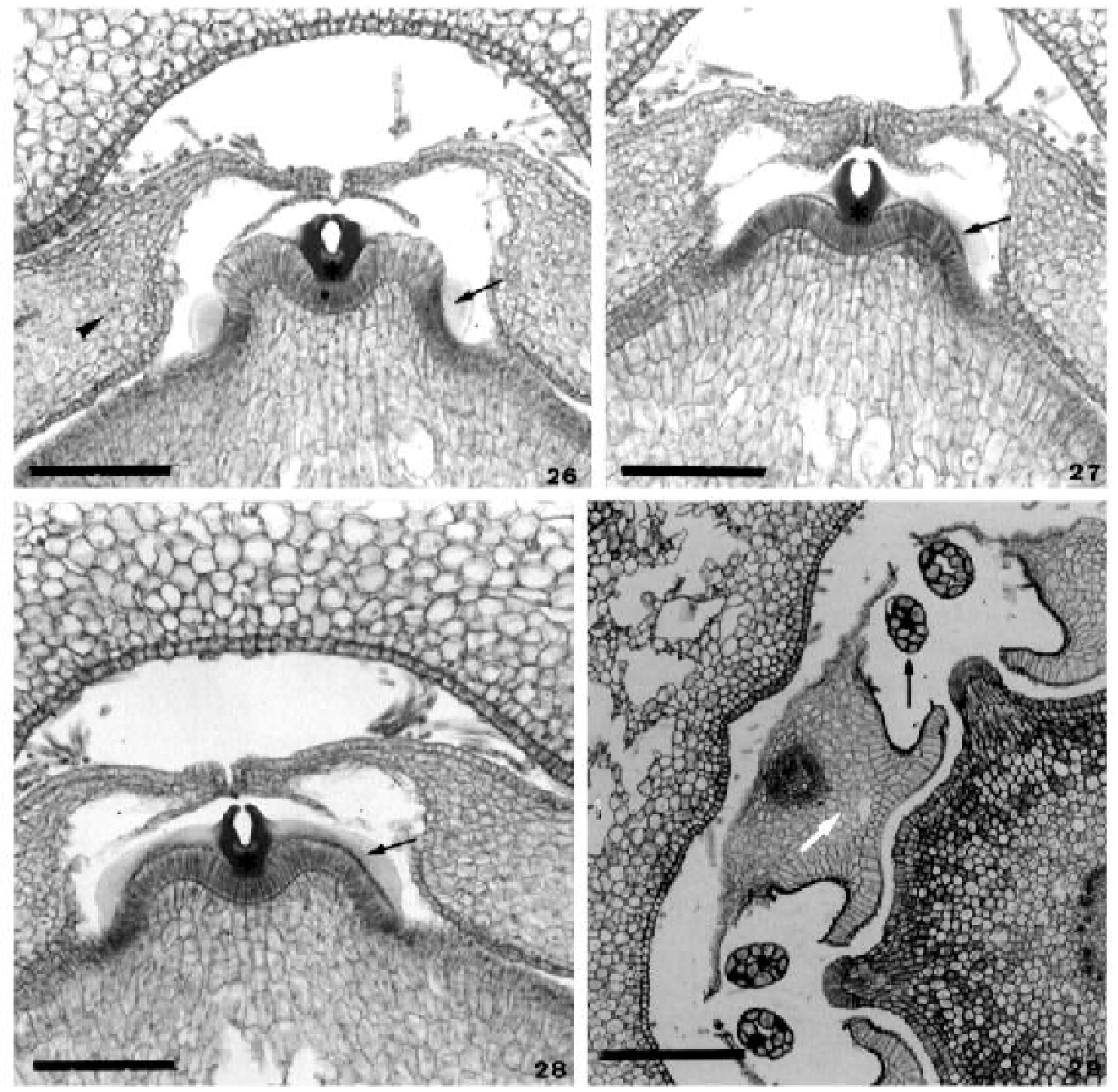

Figuras 26-29 - Botão floral (ST): 26 - formação das caudículas nas laterais da protuberância da cabeça estilar; 27 - retináculo, unindo-se a uma das caudículas; 28 - translador já formado, retináculo e caudículas; 29 - polínias localizadas fora dos lóculos das anteras, após abertura dos estômios. (Barra $=200 \mu \mathrm{m}) \mathrm{ST}=$ secção transversal; antera $=$ ठ $;$ caudícula $=\& ;$ estame $=$ Ü $;$ retináculo $=>;$ polínia $=\#$.

A cabeça estilar, no botão floral em fase final de desenvolvimento, tem forma pentagonal, em corte transversal, com cinco ângulos e cinco faces planas, onde se alojam os estames. A epiderme que reveste a cabeça estilar é uniestratificada, formada por células em paliçada, que constituem um anel em torno da estrutura (Fig. 24). Ao nível dos ângulos, tais células tornam-se ativamente secretoras e mostram-se mais alongadas, exceto na região central, onde ocorre um sulco; as células subjacentes desenvolvem intensa atividade meristemática, dando origem a uma protuberância (Fig. 25).

A atividade secretora das células epidérmicas tem inicio nas partes laterais dos ângulos. A substância secretada, de consistência viscosa, aos poucos vai-se depositando como duas placas, que acompanham o contorno da região e que, após oxidação, vão constituir as caudículas (Fig. 26). Posteriormente, essa secreção passa a ser produzida também no 

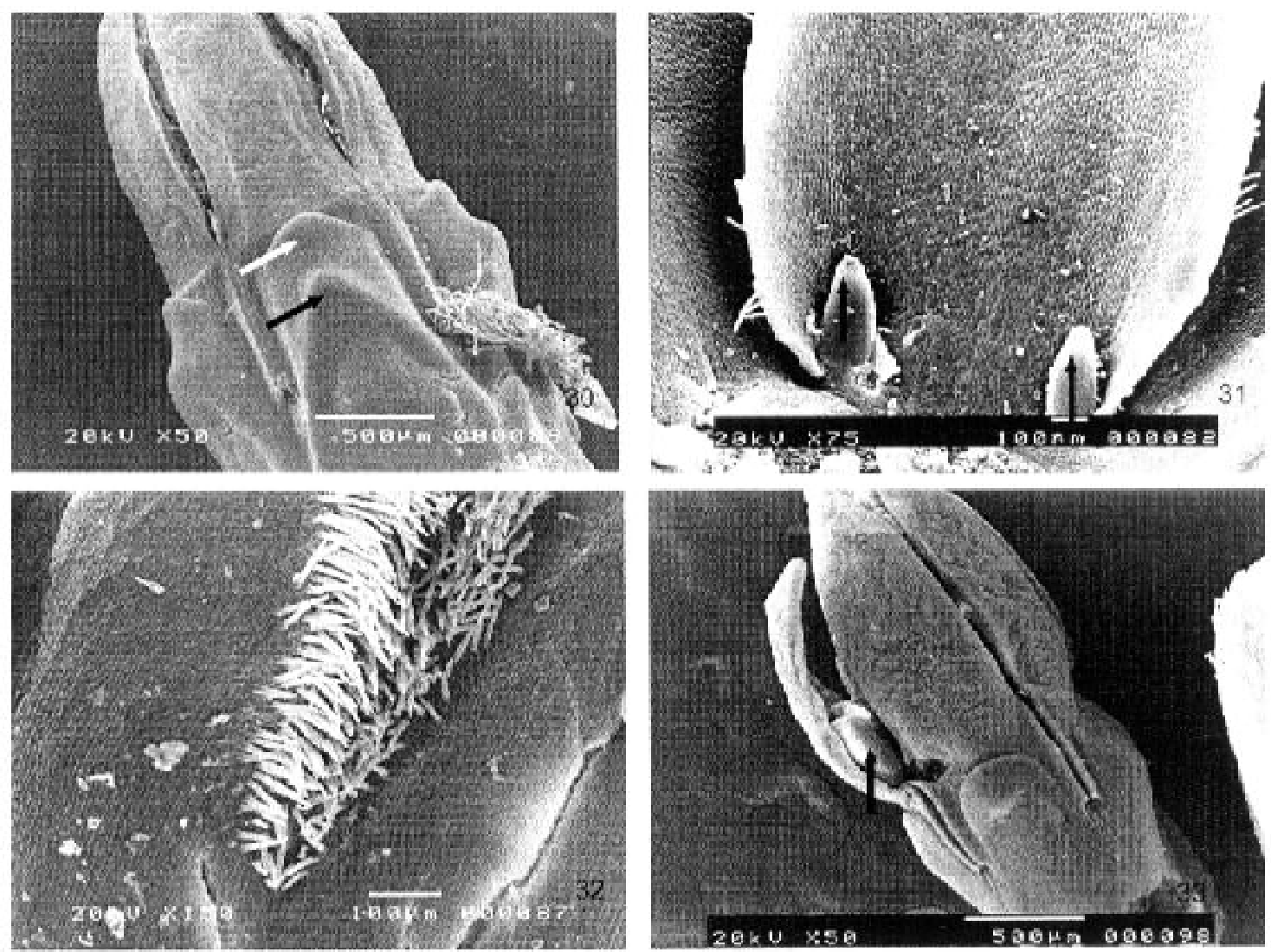

Figuras 30-33 - Botão floral (MEV): 30 - corona, no dorso de uma antera; 31 - emergências glandulares na face adaxial do tubo da corola; 32 - tricomas na face adaxial do tubo da corola; 33 - detalhe de uma polínia ereta, entre os apêndices membranáceos de duas anteras contíguas. Antera $=\circlearrowright$; corona $=\&$; emergência glandular (fig. 31) = \#, polínia (fig. 33) = \#.

sulco central, e dá origem a uma lâmina córnea, de coloração avermelhada - o retináculo (Fig. 27). Finalmente, as caudículas e o retináculo unem-se para constituir o translador, observando-se que a coloração das caudículas é menos intensa que a do retináculo (Fig. 28).

No prolongamento da cabeça estilar, em direção ao ápice, as faces planas da cabeça estilar tornam-se convexas, vendo-se, em secção transversal, que as anteras ocupam posição frontal em relação a essas faces (Fig. 29). A epiderme da antera é uniestratificada, com células de forma variada e cutícula delgada. Na face dorsal da antera, ocorre um feixe vascular anficrival, envolvido pelas células parenquimáticas do conectivo. Subjacente aos lóculos das anteras, ocorre o endotécio com células alongadas, cujas paredes apresentam barras de espessamento (Fig. 29).
No interior de cada lóculo, ocorre uma polínia que, na maturidade, adquire cor, forma e solidez características. Num estádio mais avançado de diferenciação, após a abertura dos estômios, as polínias são observadas fora dos lóculos, entre os apêndices membranáceos de anteras contíguas (Figs. 29 e 33).

\section{Discussão e Conclusões}

Os trabalhos consultados sobre o gênero Marsdenia referem-se exclusivamente aos aspectos taxonômicos, não se tendo conhecimento de qualquer estudo anatômico a respeito. Entretanto, deve-se salientar que os aspectos anatômicos observados em Marsdenia loniceroides correspondem às características gerais, mencionadas por Solereder (1908) e Metcalfe \& Chalk (1965), para Asclepiadaceae. 
Feixes vasculares bicolaterais e laticíferos contínuos, assinalados em Marsdenia loniceroides, figuram entre os aspectos apontados por Solereder (1908) e Metcalfe \& Chalk (1965). Foram referidos de nove a dez feixes vasculares colaterais nos carpelos. Destes, os dois menores, localizados na base da placenta e o maior, na face oposta, foram denominados, respectivamente, feixes marginais secundários e feixe dorsal, segundo Puri \& Shiam (1966). Marsdenia loniceroides tem placentas bilobadas, vascularizadas por dois pequenos feixes que originam os traços ovulares, características que, assim como a placentação marginal, são comuns às espécies da família (Puri 1952).

Entre as estruturas típicas da flor das Asclepiadoideae, figuram as emergências glandulares, localizadas entre as sépalas e o tubo floral. A origem destas estruturas foi pesquisada, entre outros, por Decaisne (1844), Fournier (1885), Schumann (1895), Malme (1900), Hoehne (1916), Meyer (1944), Occhioni (1956), Fontella-Pereira (1965) e mais recentemente Spellman (1975), autores que se referiram às mesmas como "glândulas".

Por sua vez, Rao \& Ganguli (1963), também pesquisaram a origem dessas estruturas e as denominaram "protuberâncias glandulares" e "escamas", considerando sua origem diversificada, nas diferentes espécies. Segundo os autores citados, em alguns casos, elas se originavam do receptáculo, "em posição alternante com os lobos das sépalas e não do cálice"; outras eram oriundas do cálice, alternando com as sépalas; outras provinham da superfície interna das sépalas e outras, ainda, originavam-se das porções laterais internas das sépalas. Ainda, de acordo com Rao \& Ganguli (1963), as "escamas" não são vascularizadas.

Em Marsdenia loniceroides, essas estruturas também não são vascularizadas e têm origem nas porções laterais internas das sépalas, corroborando a última descrição acima referida de Rao \& Ganguli (1963).
Fontella-Pereira (1977), estudando o gênero Tassadia deu o nome de emergências glandulares a estruturas semelhantes, localizadas na base do cálice. Neste trabalho, as estruturas assinaladas são consideradas emergências, segundo conceito de Uphof (1962) e Esau (1965) e, dada a sua natureza secretora, foram denominadas emergências glandulares.

Desde Schumann 1895 (apud Puri \& Shiam 1966) as "protuberâncias" das lacínias da corola e das anteras foram descritas como "corona" e distinguidas em corona externa, média e interna. Contrariando tal opinião, Woodson (1941), advogou o uso do termo "corona" de maneira muito restrita. Segundo este autor, a verdadeira corona "consists of various elaborations from the staminal filaments only". Isto porque de acordo com a denominação anterior, a "corona externa" de um grupo poderia ser facilmente confundida com a "corona interna" de outro, em conseqüência do suprimento vascular de um ou de outro verticilo da corona.

Valente (1977; 1995 e 2003) analisou, respectivamente, as flores de Oxypetalum banksii Schult. subsp. banksii, Matelea maritima subsp. ganglinosa (Vell.) Fontella e Peplonia asteria (Vell.) Fontella \& A. E. Schwarz, no que diz respeito à origem das coronas, concluindo que a corona, nessas espécies, tem origem diversificada. Quanto à vascularização, está presente apenas em Matelea maritima subsp. ganglinosa. $\mathrm{Na}$ espécie aqui analisada, constatou-se que a corona é representada por cinco segmentos não vascularizados e tem origem estaminal.

Em relação aos transladores, as opiniões divergem quanto à terminologia. Assim, o retináculo foi denominado de "glands of the stigma" por Brown, (1809); "glands" por Jussieu, Payer (in Corry 1883); Woodson (1941; 1954) usou indiscriminadamente, os termos "glands" e "translator arm", enquanto Deshpande \& Joneja (1962) denominaram essa estrutura de "corpusculum". 
As caudículas foram mencionadas como "filiform process" por Brown (1809); "processes", "arm", "caudiculum" ou "apendices" por Corry (1883); "corpusculum" por Woodson (1941) e "retinaculum" por Deshpande \& Joneja (1962).

Brown (1809) foi o primeiro a observar o modo de formação dos transladores, usando o termo "glands of the stigma" para referir o retináculo quando inteiramente formado, o que corresponde a uma idéia equivocada; visto que o retináculo não é uma glândula e sim, o produto de uma secreção.

Corry (1882) observou nas flores de Asclepias cornuti Decne. e de outros gêneros e espécies da família, os mesmos sulcos descritos por Brown (1809) na "cabeça do estilete, revestidos por uma epiderme colunar de células secretoras que exsudavam uma substância adesiva, gomosa que dava origem a uma lâmina endurecida de consistência córnea ou "cartilaginosa" que, ao secar, tornava-se escura ou amarelo-acastanhada".

Em Marsdenia loniceroides, verificouse que a cabeça estilar apresenta cinco sulcos, revestidos por epiderme de células secretoras, corroborando as investigações de Brown (1809) e as de Corry (1883). Confirmou-se também que, nesta espécie, o desenvolvimento dos transladores (retináculos e caudículas), processa-se da maneira descrita por Brown (1809). Mais recentemente, Valente (1977, 1995 e 2003), analisando as flores de Oxypetalum banksii subsp. banksii, Matelea maritima subsp. ganglinosa e Peplonia asteria, chegou a conclusões semelhantes.

$\mathrm{Na}$ espécie aqui analisada, ocorre uma intensa atividade secretora nas células que revestem os sulcos da cabeça estilar. Tal substância, ao se oxidar, origina, em separado, o retináculo e as caudículas que, posteriormente se unem originando o translador. Neste ponto discorda-se de Woodson (1941) que postulava que as caudículas eram originadas pela secreção tapetal.
Safwat (1962) constatou através de estudos ontogenéticos que os transladores se originam pela atividade das células secretoras da "cabeça do ginostégio". O presente estudo revelou que, em Marsdenia loniceroides, a atividade secretora, que dá origem aos transladores, é exercida apenas pelas células localizadas nas regiões central e laterais dos sulcos da cabeça estilar.

A parte terminal, dilatada, do estilete ou dos estiletes, é geralmente chamada de estigma, termo reservado por autores recentes apenas à porção receptiva do estigma. Por esse motivo alguns autores referem-se àquela parte dilatada como a cabeça do estilete (Willis 1955) ou cabeça do estigma (Rendle 1938).

O termo estigma para a estrutura inteira alargada é, entretanto, muito conveniente em descrições morfológicas que geralmente não levam em consideração se a superfície inteira ou somente parte dela são verdadeiramente receptivas para o pólen. Na maioria da literatura o termo é usado nesse sentido geral.

Rao \& Ganguli (1963) descreveram a anatomia floral de 12 espécies de Asclepiadaceae, observando que em 11 delas ocorria uma adnação entre a parte basal do tubo estaminal e a base do tubo da corola, o que foi também detectado na espécie em estudo. Rao \& Ganguli (1963) denominaram essa estrutura de "tubo floral", em substituição ao termo "tubo corola-androceu", opinião corroborada neste trabalho.

\section{Agradecimentos}

À Dra. Nilda Marquete Ferreira da Silva pela colaboração, incentivo, críticas e sugestões apresentadas no transcurso deste trabalho; ao Dr. Jorge Fontella Pereira especialista da família, pela determinação do material botânico, ao Dr. Ary G Silva, pelo envio do material; ao Prof. Osnir Marquete por sua participação na confecção das fotomicrografias; ao Biólogo Paulo Botelho de Macedo pela arte gráfica; à Aline Cerqueira Cardoso, estagiária, pelo preparo das lâminas; 
à Patricia Fabiane Marquete Capaz, pela versão para inglês do Abstract e ao Conselho Nacional de Desenvolvimento Científico e Tecnológico (CNPq), pela bolsa concedida à segunda autora.

\section{REFERÊNCIAS Bibliográficas}

Barroso, G. M., Peixoto,A. L., Costa, C. G., Ichaso, C. L. F., Guimarães, E. F. \& Lima, H. C. 1986. Sistemática de Angiospermas do Brasil. Asclepiadaceae. 3: 16-52, figs. 135-210.

Brown, R. 1811 (1809-1811). On the Asclepiadeae a natural order of plants separated from the Apocinea of Jussieu, London. Reprinted form. Mem. Wern. Soc. 1: 12-78.

Cronquist, A. 1981. An integrated system of classification of flowering plants. Columbia Universsity Press, New York.

Corry, T. H. 1882. On the mode of development of the pollinium in Asclepias cornuti Decaisne. Trans. Linn. Soc. London, Bot. ser. 2. 2: 75-84, pl. 16.

1883. On the structure and development of gynostegium and the mode of fertilisation in Asclepias cornuti. Trans. Linn. Soc. London 2: 173-207.

Decaisne, J. 1844. Asclepiadeae in DC. Prodromus 8: 490-665.

Deshpande, B. D. \& Joneja, P. 1962. Studies in Asclepiadaceae I. Morphology and embryology of Leptadenia pyrotechnica Decne. Phyton 19(1): 73-84.

Endress, M. E. \& Bruyns, P. V. 2000. A revised classification of Apocynaceae s.l. Bot. Rev. 66(1): 1-56.

Esau, K. 1965. Plant anatomy, New York, $2^{\mathrm{a}}$ ed., John Wiley \& Sons, Inc. 767 p.

Fallen, M. E. 1986. Floral structure in the Apocynaceae: Morphological, functional and evolutionary aspects. Bot. Jahrb. Syst., Pflanzengeschi. Pflanzengeogr. 106(2): 245-286.
Fontella-Pereira, J. 1965. Contribuição ao estudo das Asclepiadaceae Brasileiras, I. Arq. Jard. Bot. Rio de Janeiro 18: 179-182.

1977. Revisão taxonômica do gênero Tassadia Decaisne (Asclepiadaceae). Arq. Jard. Bot. RJ, 21: 235-392.

Fournier, E. 1885. Asclepiadaceae in Martius, Flora Brasiliensis 6(4):189-332, pl. 50-98.

Hayat, M. A. 1981. Principles and Techniques of Electron Microscopy. London. Edward Arnold.

Hoehne, F. C. 1916. Monografia das Asclepiadaceae Brasileiras (Monographia Asclepiadacearum Brasiliensium). Oxypetalum R. Br. Comm. Linha Telegraf. Estrat. Matto-Grosso ao Amazonas, Publ. 38, fasc. 1: 1-131, 59 pls.

Holm, R. W. 1950. The American species of Sarcostemma R.Br. (Asclepiadaceae). Ann. Missouri Bot. Gard. 37: 477-560.

Judd, W. S., Sanders, R. W. \& Donoghue, M.J. 1994. Angiosperm family pairs: Preliminary phylogenetic analyses. Harvard Pap. Bot. 5: 1-51.

Johansen, D. 1940. Plant Microtechnique. New York. McGraw-Hill Book Company, Inc. $523 \mathrm{p}$.

Kunze, H. 1990. Morphology and evolution of the corona in Asclepiadaceae and related families. Trop. Subtrop. Pflanzenwelt. 76: $1-49$.

1993. Evolution of the translator in Periplocaceae and Asclepiadaceae. Pl. Syst. Evol. 185: 99-122.

. 1994. Ontogeny of the translator in Asclepiadaceae s.str. Pl. Syst. Evol. 193: 223-242.

1995. Floral morphology of some Gonolobeae (Asclepiadaceae). Bot. Jahrb. Syst. 117(1/2): 211-238.

Kunze, H. 1996. Morphology of the stamen in the Asclepiadaceae and its significance. Bot. Jahrb. Syst. 118: 547-579. 
Liede, S. 1996. Anther differentiation in the Asclepiadaceae - Asclepiadeae: form and function. In W. G D‘Arcy \& R. C. Keating (eds.). The anther: form, function and phylogeny. Cambridge University Press. Cambridge, 221-235 pags.

\& Kunze, H. 1993. A descriptive system for corona analysis in Asclepiadaceae and Periplocaceae. Pl. Syst. Evol. 185: 275-284.

Luque, R.; Sousa, H. C. \& Kraus, J. E. 1996. Métodos de coloração de Roeser (1972) modificado. Acta Botanica Brasilica.

Malme, G. O. A. 1900. Die Asclepiadaceen des Regnell'schen Herbars, Kongl. Svenska Vetensk. Akad. Handl., 34(7): 1101, 8 tab.

Metcalfe, C. R. \& Chalk, L. 1965. Anatomy of Dicotyledons. Asclepiadaceae. Vol. II: 917-925. Claredon Press, Oxford.

Meyer, T. 1944. Asclepiadaceae in Descolei Genera Species Plantarum Argentinarum 2: 1-273, 1-121 pl.

Occhioni, P. 1956. Contribuição ao estudo do gênero Oxypetalum. Com especial referência às spp. do Itatiaia e Serra dos Órgãos (Tese). Arq. Jard. Bot. Rio de Janeiro 14: 37-210, 62 pl.

Puri, V. 1952. Placentation in Angiosperms. Bot. Rev. 18(9): 603-651.

. \& Shiam, R. 1966. Studies in floral anatomy VIII. Vascular anatomy of the certain species of the Asclepiadaceae with special reference to corona. Agra University Journal of Research 15: 189-216.

Rao, V.S. \& Ganguli, A. 1963. The floral anatomy of some Asclepiadaceae. Proc. Ind. Acad. Sci. 57B: 15-44.

Rendle, A. B. 1938. The Classification of Flowering Plants. Vol. II. Dicotyledons. Cambridge.

Rosatti, T. J. 1989. The genera of suborder Apocyninéae (Apocynaceae and Asclepiadaceae) in the Southeastern United States. J. Arnold Arbor. 70(3/4): 307-401, 443-514.
Safwat, F. M. 1962. The floral morphology of Secamone and the evolution of the pollinating apparatus in Asclepiadaceae. Ann. Missouri Bot. Gard. 49: 95-129.

Sass, J.E. 1940. Elements of Botanical Microtechnique. McGraw-Hill Book Co., Inc. New York London. 222 p. ilust.

Schumann, K. 1895. Asclepiadaceae in Engler u. Prantl. Nat. Pflanzenf. 4 (2):189-306., fig. 62-92..

Sennblad, B. \& Bremer, B. 1996. The familial and subfamilial relationship of Apocynaceae and Asclepiadaceae evaluated with $r b c L$., data. Pl. Syst. Evol. 202: 153-176.

Solereder, H. 1908. Systematic anatomy of the Dicotyledons. Vol. I: 534-537. Claredon Press, Oxford.

Spellman, D. L. 1975. New combinations in Asclepiadaceae. Phytologia 25(7) 438.

Swarupanandan, K.; Mangaly, J. K., Sonny, T. K., Kishorekumar, K. \& Bash, C. S. 1996. The subfamilial and tribal classification of the family Asclepiadaceae. J. Linn. Soc., Bot. 120: 327-369, 243 figs.

Uphof, J. C. Th. 1962. Plant Hairs. Gebruder Borntraeger. Berlin.

Valente M. da C. 1977. A flor de Oxypetalum banskii Roem. Et Schult. subsp. banksii. Estudo da anatomia e vascularização (Asclepiadaceae). Rodriguésia 29(43): 161-283, 88 figs.

1995. Matelea maritima subsp. ganglinosa (Vell.) Font. Anatomia e vascularização floral (Asclepiadaceae). Arch. Jard. Bot. Rio de Janeiro 33 (1): 75-98, 35 figs.

Valente, M.da C. 2003. Estudos morfológicos da flor de Marsdenia loniceroides E. Fournier e da origem das coronas e dos transladores em espécies da subfamília Asclepiadoideae (Apocynaceae). Tese de Doutorado.

Willis, J. C. 1955. ADictonary of the Floweing Plants and Fern. Cambridge. 
Woodson, R. E. Jr. 1941.The North American Asclepiadaceae. I. Perspective of the Genera. Ann. Missouri Bot. Gard. 28(2): 193-244.
1954. The North American Species of Asclepias L. Ann. Missouri Bot. Gard. 41(1): 1-211. 
